\title{
Human Factors in Aviation Disasters of Military Jet Aircraft of Czechoslovakia and the Czech Republic
}

\author{
O. Zavila* \\ Department of Air Force, University of Defence in Brno, Czech Republic \\ The manuscript was received on 10 October 2020 and was accepted \\ after revision for publication as technical information on 13 March 2021.
}

\begin{abstract}
:
The article deals with aviation disasters from 1948 to the present and it involves disasters of military jet fighter, fighter-trainer and trainer aircraft. It focuses on the role of human factors of the flight personnel. Based on the extensive analyses of circumstances and causes of individual aviation occurrences, root causes of factors that have endangered the lives of pilots in carrying out their work are determined. To conclude, recommendations are given to reduce or in many cases even to eliminate the effects of these factors on flight safety.
\end{abstract}

\section{Keywords:}

aviation disaster, human factors, lifestyle, mental hygiene, mental state, military jet fighter, pilot

\section{Introduction}

Aviation disasters can be definitely considered the most serious type of air accidents, as they always involve human death. According to the Všeob-P-10 Flight Safety Regulation [1], in force until recently, aviation "disaster" was defined as a type of aviation accident in which the lives of aircraft crew members or passengers were lost. The now in force Order of the Minister of Defense No. 13/2016 of the Journal [2], which replaced the above regulation, expands and generalizes the original definition under the term "Aviation Accident" without a more detailed breakdown. It is defined as: "...an event associated with the operation of an aircraft which, in the case of a manned aircraft, takes place between the time in which any person boards the aircraft with the intention of flight until the time in which all these persons have disembarked; or in the case of an unmanned aircraft, takes place between the time the aircraft is ready to move with the purpose of flight until the time when it comes to rest at the end of the flight and the primary propulsion system is shut down, in which:

\footnotetext{
* Corresponding author: Department of Air Force, University of Defence in Brno, Kounicova 156/65, CZ-662 10 Brno, Czech Republic. Phone: +4209734452 06, E-mail: ondrej.zavila@unob.cz.ORCID0000-0002-9283-0399.
} 
- a person is fatally or seriously injured as a result of:

- being in the aircraft,

- direct contact with any part of the aircraft, including parts which have become detached from the aircraft,

- direct exposure to jet blast,

- (except when the injuries are from natural causes, self-inflicted or inflicted by other persons, or when the injuries are to stowaways hiding outside the areas normally available to the passengers and crew);

- the aircraft sustains damage or structural failure which adversely affects the structural strength, performance or flight characteristics of the aircraft, and would normally require major repair or replacement of the affected component, except for engine failure or damage, when the damage is limited to a single engine, (including its cowlings or accessories), to propellers (rotor blades), wing tips, antennas, probes, vanes, tires, brakes, wheels, fairings, panels, landing gear doors, windscreens, the aircraft skin (such as small dents or puncture holes) or minor damages to main rotor blades, tail rotor blades, landing gear, and those resulting from hail or bird strike, (including holes in the radome);

- the aircraft is missing or is completely inaccessible."

As it is apparent from the citation above, the Order of the Minister of Defense currently in force merges the formerly distinguished terms (disaster, crash and damage) into one common technical term "aviation accident". However, as a result of a decision made by the author of this study, only occurrences complying with the previously applicable definition of aviation "disaster" according to the Všeob-P-10 Flight Safety regulation are included in the study. This is because the range of causes of aviation disasters is often clearly different from that related to less serious air crashes (aviation accident associated with the destruction of an aircraft without loss of life of crew members) or damage (aviation accident associated with repairable damage to an aircraft without loss of life of crew members). According to the author's belief and long-term experience, this approach makes it possible to better profile the root factors of causes threatening the lives and health of flight crews, which is the primary task of this study.

\section{Statistics of Aviation Disasters}

Between 1948 and 2019, there occurred a total of 217 aviation disasters involving military jet fighter, fighter-trainer and trainer aircraft operated in the service of the former Czechoslovakia or the present Czech Republic (see Fig. 1 below). In 39 cases, the aircraft crew tried to eject, in 43 cases dual-control aircraft were involved and 27 cases were collisions in flight.

A total of 265 persons on board were directly involved in these aviation disasters; 256 of them were killed. Out of 9 survivors, 4 crew members rescued themselves ejecting successfully and 5 crew members escaped the situation without having to eject (finished the flight by landing successfully). 38 persons were killed in unsuccessful ejections; 74 were killed in dual-control aircraft and 29 in collisions in flight. Among the victims, 6 pilots were foreign nationals ( 1 from the former Soviet Union, 2 from Indonesia, 1 from Iraq, 1 from Libya and 1 from Algeria) performing or participating in flight trainings in former Czechoslovakia.

Aviation disasters in the former Czechoslovakia and the Czech Republic occurred in 33 versions of 12 types of military jet aircraft. Only 4 types of aircraft were not 
affected: the original German Messerschmitt Me-262 "Schwalbe" (in post-war Czechoslovakia assembled and operated under the designations of Avia S-92 and Avia CS92), the Soviet Sukhoi Su-25 and Mikoyan-Gurevich MiG-29, and so far the Swedish Saab JAS-39 Gripen.

Information on the aviation accidents in question, mainly in the form of original investigation reports and additional expert analysis reports, was obtained through long-term collection from military archives [3-5], aviation literature [6-10] and continuously updated personal testimonies of surviving veterans and witnesses. The purpose of this effort was to achieve the maximum possible accuracy of interpretation of historical data.

Further detailed information on these aviation disasters can be found in the literature [11].

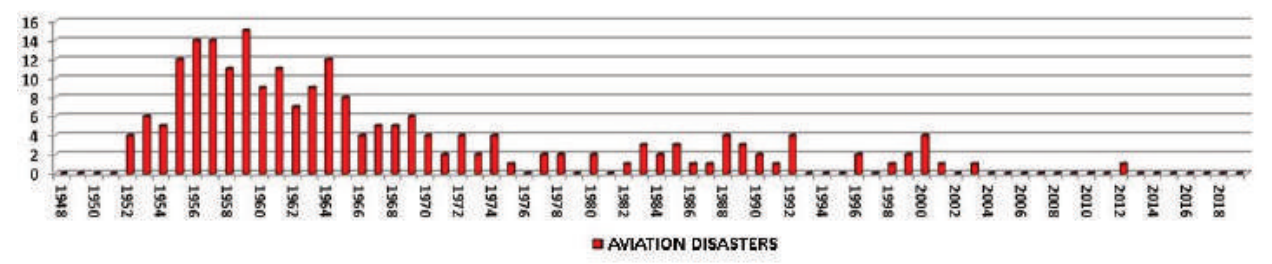

Fig. 1 Aviation disasters in jet fighter, fighter-trainer and trainer aircraft in Czechoslovakia and the Czech Republic on a timeline

\section{Analysis of the Causes of Aviation Disasters}

Subject to the analysis was a set of all 217 traceable aviation disasters which occurred between 1948 and end of 2019 in military jet fighter, fighter-trainer and trainer aircraft in the service of the former Czechoslovakia and the present Czech Republic.

Each disaster was analyzed under 21 criteria divided into 4 groups: timing details (date, time, day of the week and season), data on aircraft (type, version, tail code or serial number, on-board ejection seat type, aircraft's base unit assignment), data on crew (name, rank and title, age, flight hours, pilot class rating, service ranking) and data on aviation disaster circumstances (main cause factor, main cause, stage of flight, weather, ejection conditions if applicable, brief description of the event).

All the information obtained was systematically entered on the Microsoft Excel spreadsheet in order to further analyze individual criteria using various filter functionalities.

The aim of the analysis was to find out any common features, differences and specific features interesting from the flight safety point of view. The information acquired was then divided into two groups: "still relevant" (as yet unresolved problems) and "no longer relevant" (now obsolete problems). The problems falling under "still relevant" were put in relation to each other and subjected to further analysis. The resulting logical links and rules were then formulated both in the text and in graphics (see below).

\subsection{Overview of the Causes}

Fig. 2 shows the interpretation of numbers and percentage of individual main cause factors and main causes of the aviation disasters analyzed. Every aviation accident is caused by a chain of causes, which most often consists of three to five elements (cir- 
cumstances) acting simultaneously or consecutively, both type and course of which result in a disastrous outcome.

In the context of this study, the "main reason" is the part of the chain that was of paramount importance for the development of the disastrous situation or the part of the chain where the disastrous situation could still have been averted. The main reasons can be divided into 4 groups collectively referred to as "main cause factors": technical factors, environmental factors, human factors (of flight and non-flight personnel) and not found [1]. To express the percentage of both main cause factors and main causes, the number of 217 disasters is regarded as the base (100\%).

The graphic presentation below shows the predominance of "human factors" with a share of as much as $80 \%$ of the total (i.e. 175 out of the total of 217 occurrences). Within the human factors, the "flight personnel" group prevails with a share of $50 \%$ of the total (i.e. 110 out of the total of 217 occurrences). Other main cause factors are represented only in smaller numbers.

What is surprising is only a relatively large number of events whose cause was "not found". This is generally because flight data recorders were either not installed at all over a long period time in the past or they had technical limitations; or it was due to extensive damage to the aircraft.

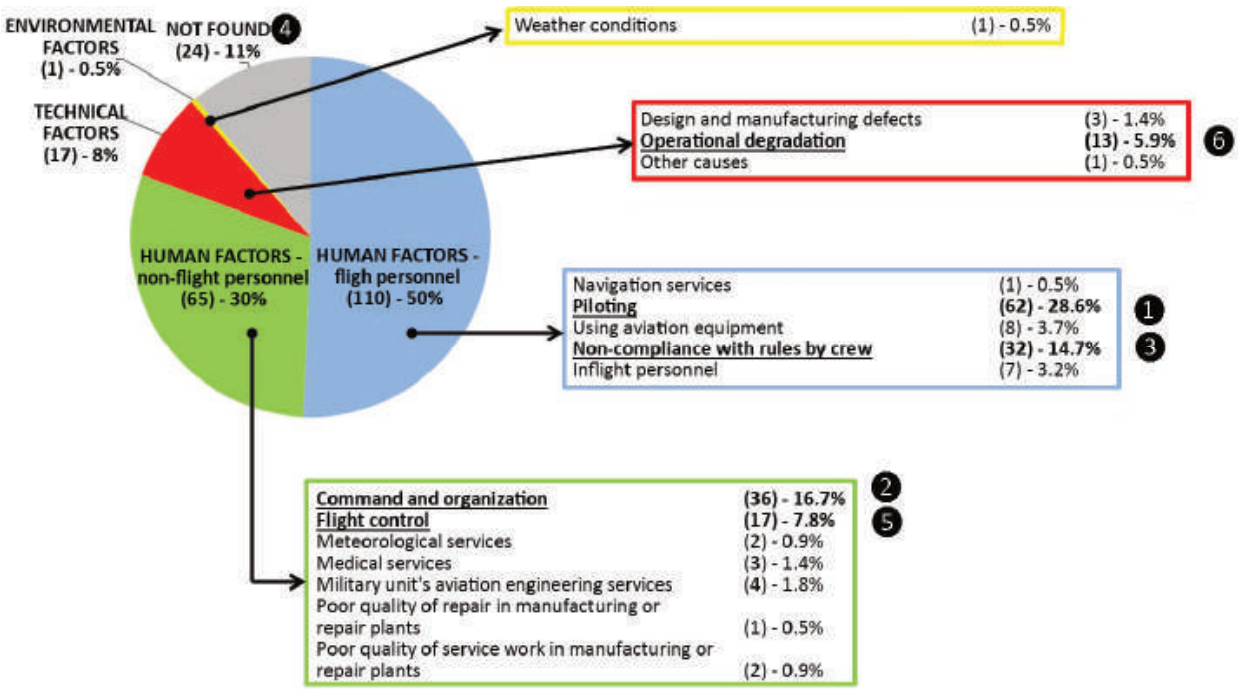

Fig. 2 Main cause factors and main causes of aviation disasters in military jet fighter, fighter-trainer and trainer aircraft of Czechoslovakia and the Czech Republic between 1948 and 2019 (classified in accordance with regulation V̌̌eob-P-10 Flight Safety [1])

Fig. 2 shows that "piloting", "command and organization" and "noncompliance" predominate among the main causes ranking first through third. The other main causes are represented to a lesser extent and fortunately most of them can currently be considered "no longer relevant".

Most of the technical problems of aircraft technology evaluated in this study no longer exist as they were associated with aircraft technology that is not in operation any more. In addition, the rules of command and organization, flight control, meteorological security and aircraft maintenance management have changed significantly and the problems identified in earlier times are not encountered any more. Although the 
environmental factors have not changed in relation to meteorological conditions, with the functionality of other systems and technical elements its influence is statistically proven to be minimal.

However, what have not substantially changed over the last 70 years are the main causes falling under "human factors - flight personnel" category. They are among the causes of aviation disaster which are "still relevant" and, as such, will be given major attention in the following text (especially see Section 4 below).

\subsection{Causes of Unsuccessful Ejections}

In 39 cases (approx. $18 \%$ ) out of the total of 217 aviation disasters, at least one crew member tried self-rescuing by ejecting himself. The ejection was unsuccessful for 38 crew members; only for 4 crew members it was successful.

In most cases, the reason for those failures was that the crew member decided too late to eject (typically at an already too low altitude). Exceptions to this are two cases when despite having ejected successfully, the Czechoslovak pilots were killed due to a technical defect of ejection seats (disasters of May $5^{\text {th }} 1964$ in the MiG-15T and of November $20^{\text {th }} 1969$ in the Su-7BM).

According to the findings so far, the crew's late decision to eject was due to one of 5 causes or a combination of them:

- insufficient training,

- noncompliance with rules and regulations,

- fear of legal sanctions (especially if the pilot believed he was the only one to be responsible for the emergency),

- altruism (if the pilot believed that a crashing aircraft could endanger the lives and health of people on the ground),

- unexpected psycho-physiological response to stress (change in the state of consciousness mainly due to a high $G$ during certain maneuvers resulting in an unpredictable subconscious reaction to a stressful, entirely external stimulus).

Most of these causes could still be relevant today for many pilots. It is therefore necessary to address their nature before flight, ideally already during flight training. Modern ejection seats enable successful ejection even at zero altitude and zero speed of the aircraft and thus, this increases the likelihood of the pilot's successful rescue. However, the time factor of the decision to use those means remains the most important as even the most advanced ejection seats require certain time and space to execute their functional procedure fully and thus successfully.

\subsection{Causes of Disasters in Dual-Control Aircraft}

Disasters in trainer and fighter-trainer dual-control aircraft accounted for less than $20 \%$ (43 cases) of all occurrences. In over half of the cases they were caused by "piloting" errors and "noncompliance" and also, to a lesser extent, by errors in "command and organization", "flight control" or "design and manufacturing defects". Specific root causes of these occurrences include insufficient pre-flight preparation, underestimation of weather conditions, bad piloting habits of instructors (when switching between different types of aircraft), fatigue, or, in exceptional cases, language barrier between the pilot and instructor.

Interestingly, a problem with transitory incorrect attitude of instructors towards trainees was often present. In most cases, this was not an intentional practice, but ra- 
ther a subconscious behavior that resulted from specific situations and psychological profiles of the instructors.

Instructors are usually appointed from the rank of active fighter pilots, who can be briefly characterized as intelligent, very active, confident, naturally competitive individualists (individual achievers). But if a pilot who was a fighter pilot before takes up his duty as an instructor, he should radically change his priorities and attitudes towards flying. Regrettably, not all of them are able to do so.

The mission of a fighter pilot is to win the battle, whereas the mission of a flight instructor is to achieve his trainee's maximum performance. These are vastly different goals. However, sometimes it happens that the instructor forgets for a while what his role is and rekindles his reflexes of fighter (a naturally competitive) pilot - all the more so, the smaller are the differences in age and skills between the instructor and the trainee (many times the instructor's colleague). At that moment, the two pilots begin to subconsciously compete with each other and create reciprocally non-standard situations, often without effective professional communication. A lot of times the instructor waited to see how the trainee would deal with a certain situation, whereas the trainee trusted that the instructor would not allow him to make a fatal error. If this "game" is played with high intensity, it usually leads to an accident. Great attention therefore should be paid to this subconsciously occurring psychological principle.

In summary, the causes of disasters in dual-control aircraft can be described as: lack of preparation, indiscipline, fatigue and misunderstanding (arising from the fact that a pilot is over reliant on "the other one").

\subsection{Causes of Mid-Air Collisions}

Mid-air collisions accounted for about $12.5 \%$ (27 cases) of all analyzed disasters. In the past, more than $40 \%$ of mid-air collisions were caused by deficiencies in "flight control". Another $26 \%$ of collisions were caused by "piloting" errors. Acts of "noncompliance by the crew" and errors by "flight personnel" (leader or wingman in pairs of aircraft) were represented by approximately $11 \%$ each. "Command and organization" and "navigation" were only sporadic causes of mid-air collisions.

Air traffic control service erred mostly in the 1950s and 1960s because it was underequipped with radio technology instruments and also there was little experience in dealing with fast flying of jet aircraft. Groups of aircraft were literally sent on collision courses several times. In many cases, there were also inadequacies in communication between pilots, particularly in cases where the pilots momentarily lost visual contact with each other. The ergonomic design of many cockpits, inconvenient for the pilots because it considerably reduced their field of vision, had no small share too. Placement of some controls also obliged the pilots to shift their sight from outside to inside the cockpit in critical moments.

In summary, the causes of disasters in mid-air collisions can be described as: inconsistencies (mainly in air traffic control), indiscipline (failing to maintain height, speed and separation in formation flights) and ergonomic traps (in cockpits).

\subsection{Causes of Flight Indiscipline and Failure in Higher-Level Piloting Techniques}

Incorrect "piloting" was established as the main cause in $28.6 \%$ (62 cases) of the total of 217 aviation disasters analyzed, but it also occurred in many other cases as part of the chain of causes. Piloting maneuvers whose incorrect execution led to a disaster can be again divided in two categories as "no longer relevant" and "still relevant". 
At present, all types of turns and spins can be regarded as "no longer relevant". Although incorrectly executed turns and unintended undesired spins are the causes which are represented in aviation disaster statistics the most frequently (especially from 1950s through 1970s in the MiG-15s), most of them occurred in conditions where the natural horizon was not externally visible after the pilot's disorientation. This was most frequently because the pilot had forgotten to switch on the attitude indicator (artificial horizon) in good time before flying into the clouds. This problem is no longer relevant because the attitude indicator in modern fighter aircraft is activated automatically upon the initiation of on-board electrical systems. On-board systems in modern aircraft provide the pilot with a number of advance visual, text and acoustic warnings when entering any aerodynamically dangerous modes of flight.

There are other dangerous piloting maneuvers, however, that appear to be "still relevant". These are mostly vertical maneuvers (split $\mathrm{S}$, dive, loop, Immelmann) and also one horizontal one (roll). In total, the mentioned vertical maneuvers were fatal to almost the same number of pilots as spins and turns. Their hazardousness has always been caused by pilot's omission of important technical data just before entering the maneuver (too low altitude; too high airspeed; high air temperature - low air density; different aircraft weight - large amount of fuel, suspended armament, etc.). These factors influence (usually increase) the radii of circular maneuvers and therefore increased height is required for vertical maneuvers to be exited safely.

Interestingly, "still relevant" dangerous piloting maneuvers include also lowaltitude and very low-altitude rolls. To execute them properly (i.e. to rotate the aircraft around its longitudinal axis without loss of height), the pilot needs not only to have piloting skills, but also to know the actual center of gravity position of the aircraft relative to the longitudinal axis of the intended rotation and, particularly, to be aware of aerodynamic specificities of the aircraft.

The position of the aircraft's center of gravity in relation to the longitudinal axis can be affected, for example, by suspended armament or equipment (additional fuel tanks). Due to inertial forces resulting from the rotation around the longitudinal axis, the roll cannot be executed properly. Instead, a variant of "barrel roll" is formed, characterized by changes in height during rotation, which at a too low altitude may lead to a crash into the ground.

Aerodynamic specificities in some types of aircraft may include tendency to inertial rotation, which is generated when specific angular velocity values are exceeded for the rotation about the longitudinal axis. The aircraft cannot be recovered from this rotation mode as flight control surfaces become ineffective and the crew must eject. A typical example of such aircraft was the MiG-21; even in its pilot's manual the angular velocity of rotation around the longitudinal axis was strictly limited.

To sum up, vertical maneuvers clearly predominate among still relevant dangerous piloting maneuvers.

Higher piloting techniques are intrinsically linked to "flight indiscipline" (willful noncompliance of rules and regulations by the crew during the performance of a flight task). To date, three types of flight indiscipline" have been recognized:

- flight indiscipline based on pilot's attempt to know the limits of the aircraft,

- flight indiscipline based on pilot's attempt to know his own performance limits,

- flight indiscipline based on pilot's attempt to fly for exhibition.

The first flight indiscipline type is relatively the least hazardous as it is usually performed with sufficient height reserve and the pilot is fully concentrated both physically and mentally. Pros and cons of such actions are debatable. On the one hand, the 
pilot is extending his experience with flying and familiarity with the aircraft. On the other hand, he is running the risk of damaging the aircraft and its equipment or reducing their service life. What matters is the degree to which the established limit values were exceeded and also for how long. In present-day modern aircraft chances to perform such actions have been greatly diminished as the aircraft are equipped not only with complex flight data recorders, but also with "fly-by-wire" systems (electronic control systems in aircraft that highly reduce by software means the possibilities for the pilot to enter dangerous flight modes).

The second flight indiscipline type is a little more hazardous. The pilot again performs it the way he sees fit and with sufficient height reserve, but whether the height reserve is sufficient or not depends on his highly subjective estimation since nobody can accurately determine the time necessary for a human body to recover after possible collapse due to high $\mathrm{G}$ or the functioning of the aircraft when it is left uncontrolled. Such personal challenges are therefore advised to be taken on the ground under surveillance (ideally by a doctor).

The third flight indiscipline type is the most hazardous one, as it is usually carried out in an improvised way with no adequate previous preparation and in a low height. The principle of this activity is very simple. An exhibition is always performed for a particular person or group of people. In order to be appreciated, it has to be seen. In order to be seen, the exhibition has to be performed low above the ground. If the pilot descends to lower heights, he usually gets lower than the prescribed safe height is, and the safe height reserve is unacceptably small for most maneuvers. The lack of preparedness for such a performance (failure to calculate the radii of maneuvers depending on actual weight, center of gravity location, air temperature, etc.) generates a great risk of flying into the ground if parameters for entering and exiting a maneuver are estimated incorrectly. Few pilots are able to fly higher-level piloting vertical maneuvers identically with a precision of units of meters with different aircraft configured differently and under different meteorological conditions. Those units of meters are then sometimes lacking to exit safely a maneuver if it is performed in low or very low heights. Even though most cases of flight indiscipline can be traced back from records acquired from flight data recorders, this cannot be considered as an ultimate protection from them happening. The most effective protection is always the pilot's sound, logical and professional assessment of the situation.

\subsection{Causes of Cases of No Chance of the Crew's Rescue}

An interesting question is whether there were any cases among the aviation disaster occurrences where the aircraft crew had no real chance to be rescued. Unfortunately, the answer is yes. Principally, there were four types of causes for this.

The first of them is a sudden and unexpected in-flight incapacitation of the pilot when he losses consciousness or the ability to control the aircraft (that is, he is unable to perform the steps necessary for ejection). Such cases are very difficult to verify, but high probability is that there were several such cases among the disasters for which the cause could not be identified. Especially in the 1950s, the conditions provided were far from ideal for pilots to have a healthy lifestyle with quality food and a balanced exercise and rest regime and in many cases these conditions demonstrably affected their flight performance. Not all in-flight emergencies led to disasters, but a few of them surely did. At the time, a number of important pieces of information were not mentioned in investigation reports for political or personal reasons of high-ranking 
officials and we only learn the missing pieces of the stories from surviving witnesses. The causes of in-flight incapacitations also include cases when defective ammunition (mostly unguided missiles) exploded prematurely near the aircraft, thereby injuring the pilot. Others include injuries to pilots caused by aircraft collisions. It can be assumed that this was very likely the cause of the accident/disaster in more than a dozen cases.

The second irresolvable cause of aviation disaster may be the pilot's physiological response to high-G loads when executing a maneuver. High-G loads can cause partial or complete loss of consciousness of varying duration, making it impossible to use onboard rescue equipment. High-G loads can also be expected after entering unusual attitudes following the loss of orientation resulting from in-flight illusions, for example. There were up to several dozens of such cases.

The third of possible irresolvable causes are technical failures of aircraft in conditions ruling out the ejection seat safe deployment. The first ejection seats had clearly specified limits for a safe use, usually defined by the minimum and maximum flight height and speed. If the pilot flew outside those limits, his chances of surviving were very small. A typical example of such a situation was the propulsion unit failure during take-off or landing at night when the aircraft flew at a low speed and height and achieving the requisite height and speed or landing safely in unlit terrain was impossible. Among the analyzed cases, there are indeed some with similar attributes. Presentday ejection seats in aircraft no longer have most of such limitations and can be successfully deployed even at zero height and zero speed on the ground (this does not apply only if the aircraft is moving in descent or even dive headed towards hitting the ground - in such cases the minimum height for safe ejection is greater).

Finally, the fourth of irresolvable causes of disasters are technical failures of ejection seats that do not allow the successful completion of the ejection procedure. Fortunately, only two cases with this characteristic are known in Czechoslovak military aviation history (both from the 1960s), which exemplifies the high reliability of on-board rescue ejection systems so far.

Most of these causes with no chance of rescue should now be a thing of the past. Flight crews undergo intensive physical examinations every year and the technical systems in modern aircraft (such as in the Saab JAS-39 Gripen) have in-flight high-G load limitations programmed in their on-board computers. This means that at present it is practically impossible for the pilot to find himself (against the "will of the on-board computer") in conditions for which he has not been long trained or which are inadequate to his health condition and physical fitness. Also, the limits within which the systems for emergency exit of the aircraft in flight or on the ground may be used have expanded considerably.

\section{Flight Personnel Human Factors}

The analyses of aviation disasters causes in which the flight personnel human factors played a key role in the cause chain (110 occurrences) clearly show the conclusion that: "Most errors stem from LACK OF CONCENTRATION and PHYSICAL AND MENTAL DEBILITATION while, at the same time, quick ADAPTATION TO SIGNIFICANT CHANGES of conditions is needed". In other words, it has been shown that the greatest threat to fighter pilots of fixed-wing aircraft is posed by their own mental states often combined with organic physical debilitation due to inappropriate lifestyle (for more details see Section 5.2). 
The principle of increased error rate of a member of flight personnel (most often a pilot) is shown in the figure below (see Fig. 3) and can be explained as follows. Flight personnel are selected, trained and tested in a highly qualitative manner, as compared with most other professions. Those who successfully pass this selection and educational process usually show an above-standard level of mental and physical performance and their error rate in the performance of procedures already mastered is very low. It should be added that they are also usually highly motivated by the nature of their profession and also their natural survival instinct.

However, all this applies only if the exercise of their profession is not significantly interfered. The analyses of the course of development of aviation disasters have shown that the most powerful source of "interference" is the pilot's own mental states, which thereafter reduce his concentration and thus create reasons for errors and their delayed recognition. Such mental states most frequently include: excessively strong motivation, commitment, desire for recognition or competitiveness, or "personality cult" (for details see Section 5.1 below).

All this is often accompanied by physical or mental "debilitation" stemming from fatigue caused by a lack of effective rest (for details see Section 5.2 below).

"Interference" and "debilitation" of concentration create conditions for increased error rate, which is most often reflected in consequences of stretching the subjective limits of acceptable risk (endeavor to complete the task at all costs) and unfortunately also in delayed adaptability to change (slowing reflexes and ability to solve nonstandard situations). If a pilot does not adequately perceive the "warning signs" of his body, such as small piloting or procedural errors in performing the assigned tasks, this may result in an aviation accident over a certain period of time.

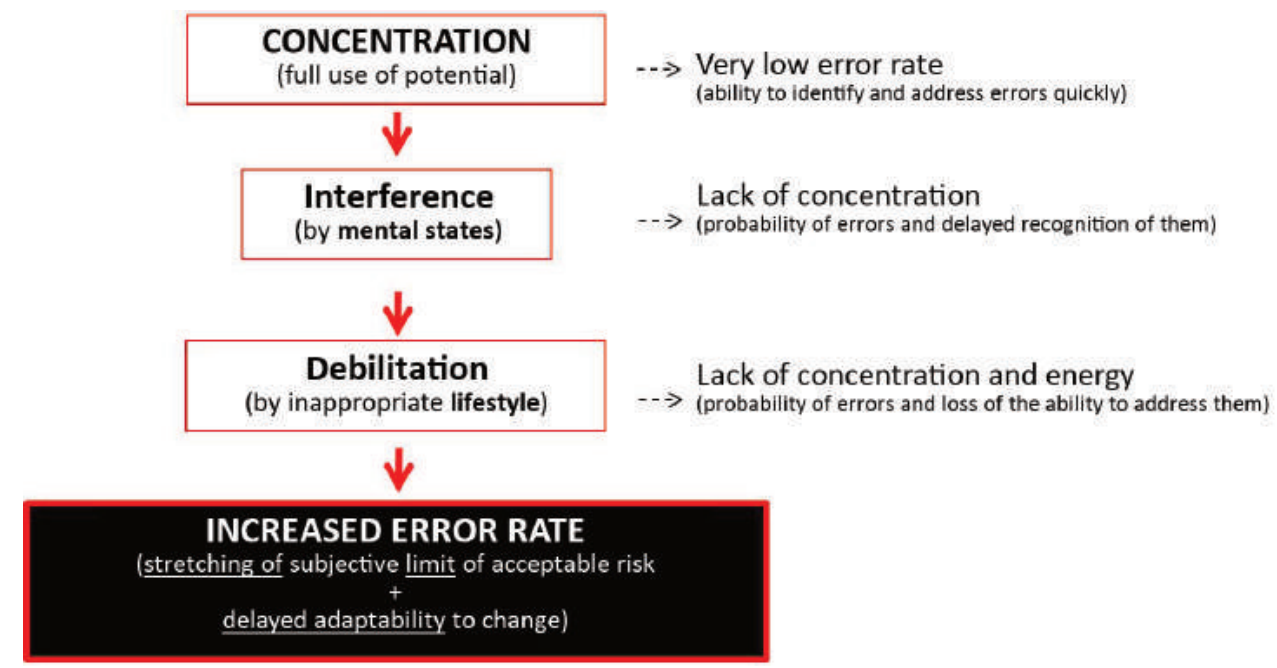

Fig. 3 Principles of development of pilot's increased error rate due to reduced concentration caused by undesirable mental states and lifestyle 


\section{Opportunities for New Trends in Flight Safety Prevention}

In the light of the facts established by the analysis (see above), a survey was conducted among the flight crew (several dozen flight crew members) based on a questionnaire focusing on awareness of the principles of proper lifestyle and mental hygiene.

It has turned out that the level of awareness in these fields is very low among the flight personnel, because these issues are hardly ever communicated to the flight personnel during their education, instruction and continuous professional training. This often leads to making unnecessary mistakes in maintaining proper lifestyle and mental hygiene, which in turn affect flight performance.

It would be therefore beneficial to raise this awareness in the future so that flight personnel know which service they should turn to if they have any problems. Also, gaining knowledge of some of healthy lifestyle and mental hygiene principles can enhance the confidence in the usefulness and effectiveness of such techniques and dispel the common myth that “... whoever needs a psychologist, psychiatrist or other therapist is certainly sick or insane ..." This is not true in the slightest, and such prejudice at present only results from a lack of knowledge. Also, receiving such services does not primarily affect the development of a professional carrier; on the contrary, not receiving them often does.

\subsection{Long-term Pilot Performance Curve - Dangerous Phases and Intervals}

To understand the origin and progress of some mental states that, under certain conditions, can be threatening to pilots, it is necessary to look at the situation in a broader context. The mental state always reflects the reaction to a specific stimulus or life situation, both personal and professional. To get a better and clearer idea of the pilot's professional situation, a model "long-term pilot performance curve" can be used (see Fig. 4) to show critical points of the pilot's professional career and also to explain their most common causes.

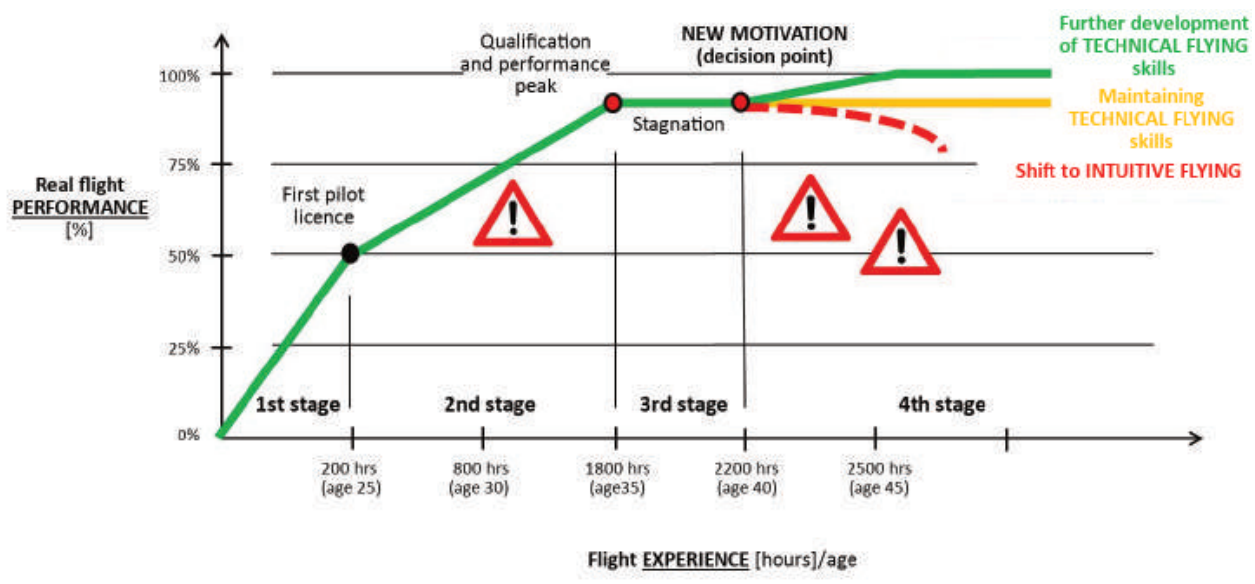

Fig. 4 Model long-term pilot performance curve

The first prerequisite for understanding the performance curve is the fact that there is often a vast difference between the "flying EXPERIENCE" and the "real flight PERFORMANCE" of a pilot. By no means are these synonyms. Flying experience is determined by the number of flight hours (the greater the number of hours flown, the 
greater the "flying experience"), while real flight performance is determined by the number of errors made by the pilot during the flight and it can be expressed as a percentage ( $100 \%$ corresponds to pilot's error-free performance). As the shape of the performance curve suggests, the relationship between flying experience and flight performance generally changes over time. The professional life of a pilot can be divided into about 4 stages.

The first stage, characterized by a significant increase in aviation performance in line with the number of flight hours, represents basic flight training. In this phase, the pilot starts from scratch and fully concentrated he realizes the full potential of the flight hours, so his flight experience is growing relatively quickly. This stage ends with the acquisition of the first pilot licenses (pilot ratings). In the Czech Republic, it is currently associated with an age of around 25 years and a practice of around 200 flight hours.

The second stage, characterized by a more slowly increasing but still upward trend in flight performance, represents flight training after joining the military unit. At that time, the pilot is getting acquainted not only with practical flying, but also with the ambiance of the airbase and its functioning. His attention is no longer focused only on flying, but he also focuses on carrier advancement. This stage lasts approximately 10 years (from 25 to 35 years of age of the pilot) and it is the first of the dangerous periods in the professional life of a pilot. The pilot usually does not yet really know the limits of his mental or physical performance and is fascinated by the dynamism of and opportunities for his professional growth. In this period, with overly strong motivation it is very easy to overestimate one's skills in hopes of gaining recognition or advancing in one's career quickly. There are usually two types of pilots: safetyoriented and mission-oriented.

Mission oriented-pilots in particular can develop a phenomenon that can be referred to as "personality cult". It is basically a self-destructive mental condition in which the pilot is unhealthily fixated on attaining his goals, loses the ability of objective self-reflection and, most importantly, he loses the ability to communicate effectively with others. The biggest problem with this condition is the inability and unwillingness to communicate, because from then on, the pilot performs tasks originally designed for a team of several people completely on his own. Then it is not a question of whether a major error occurs, but when it occurs. Most often, pilots of that age and at that stage of their professional life are threatened by ignoring their own limits and by their impatience related to performance and the associated career advancement. This problem has to be acknowledged and addressed, both by the pilot's subjective mental hygiene and from supervisor positions.

The third stage can be described as a period of slight stagnation after the pilot has reached his qualification peak. It comes between the age of 35 and 40 approximately. At that time, the pilot is at the height of professional competence and has completed everything a regular training can offer him. With experience comes balanced prudence and healthy fighting aggressiveness based on self-confidence. At this stage, pilots do not make a lot of mistakes due to human factors. This stage usually ends around the age of 40 with a moment that can be described as "decision point". This is a period in the pilot's life when his personal and professional situation often changes and the pilot decides what to do next. Very often, the order of his priorities changes, as, accordingly, does the distribution of his energy put into them.

The fourth stage starts after the "decision point" and usually has three possible scenarios: 
- further improvement of TECHNICAL FLYING skills,

- maintaining TECHNICAL FLYING skills,

- shifting to INTUITIVE FLYING.

Scenario A is rather exceptional because it requires finding motivation for further professional development even after reaching a notional qualification peak. Yet it is possible; characteristic groups for this scenario are pilots in air display teams (teams performing flight demonstrations at air events, usually for the public) or pilots in various aerobatic groups. They are able to find motivation in improving the details of piloting techniques and over time they achieve almost $100 \%$ of their potential individual flight performance.

Scenario B is characteristic of most pilots (or flight personnel) because it requires no further major development of knowledge or skills, but only some minimal effort to maintain performance above a subjectively reasonable limit. Even after reaching their notional peak performance, these pilots still take flying seriously as a profession, maintain awareness of applicable regulations and abide by the limit values indicated by the on-board equipment. Their flying is technical, within the permitted range, and their real flight performance is maintained at a high level of quality for a long time. Even though this quality level slowly decreases over time due to increasing physiological limitations of the pilot resulting from physiological wear-and-tear of the body, to some extent these limitations are compensated by experience and well-developed capacity for "predictive thinking" (that is, sense and judgment for what will happen in a short time - ability to apply logical rules to anticipate upcoming events and their potential consequences).

Scenario $\mathrm{C}$ occurs in a smaller but still quite large group of pilots who, according to statistics, considerably change their life priorities around the age of 40 , but fail to find new motivations and joys in their profession. Their attention is shifted to different spheres of their personal or professional lives and they stop paying enough attention to flying. They start relying on their "flying experience" (mostly grounded on high flight hours) and gradually move to what is called an intuitive flying (that is, flying based on a feeling and subjective estimation of situations without much respect for the limit values indicated by the on-board equipment). This is the primary reason for the start of a rapid decline in "real flight performance". A lower level of concentration and focus combined with a loss of direct feedback from the aircraft leads to a gradual weakening of basic piloting habits. Predictive thinking is not sufficiently applied and it is often replaced by a false self-confidence based only on flight experience (i.e. the number of hours flown so far). The logical consequence is an incorrect response to an emergency situation at some point, which, in extreme cases, can result in an aviation accident.

At this stage of the pilot's life, with such an approach to flying, the aforementioned "personality cult" also often appears. If may arise from two different causes, but its manifestations are basically identical for those around.

The first possible cause is primarily the defensive attitude of a person who refuses to admit his gradually decreasing real flight performance and rejects the views of other people who insinuate it. This condition is usually associated with an overly high level of motivation for attaining above-standard work results and loss of the ability to conduct two-way communication with the others. This is an "escape from reality" response, which of course is not an effective solution in the long run. There is only one solution: to accept the real situation as it is and to try to improve it again by a conscious systematic approach (that is to start working on oneself with modesty and regain one's piloting quality). If any circumstances prevent this, it is necessary to 
adjust the content of flight activities so that they are safely manageable even with reduced air performance of the pilot (even at the cost of temporary small financial loss, because of which it is certainly not worth risking an aviation accident).

The second possible cause is too strong a fixation on subjective, mostly professional goals. The pilot at that age usually reaches command positions where he has a wide range of opportunities to promote his ideas and opinions, which have so far been shaped by higher authorities. At the same time, however, as his career progresses, the pilot receives less feedback if he himself does not ask for it (because not everyone dares to point out the mistakes of their stressed and overworked superior). With higher rank there are also more administrative tasks, which take up more and more energy and time to fly. The result is often a deep dilemma between the "opportunity" to finally realize one's dreams and the "capability" to realize them through real piloting performance. If the pilot gets fixated only on his goals and stops perceiving and communicating with his environment, he will be left alone for everything and with a high probability he will sooner or later overlook important information or circumstance and commit an error. The solution to this is again to take a sober and objective view of the matter. If the pilot is promoted to command positions, in the current system as it is set it brings certain stagnation in the development of his flight skills, simply because he has less time and energy to spend on flying. It has to be accepted as a fact and further aspirations and decisions must be adapted to it.

Fortunately, people burdened with the complex life circumstances described above can now be identified in advance (for example by a continuous evaluation of flight performance records through flight operational quality assurance equipment) and it is possible to effectively help them successfully cope with this difficult situation in life (for instance, with the help of a corresponding air-base psychological service).

\subsection{Lifestyle}

Good lifestyle is a necessary prerequisite for long-term good physical fitness and physical and mental health (see Section 5.3 below), which is a basic precondition for fighter aircraft pilots to be able to exercise their profession.

It is based on 4 basic conditions: fluid intake, diet, exercise and rest. If any of them is not satisfied, the performance of the human body decreases and physical or mental illnesses may develop in the long run.

At different historical stages, flight crews had to face various shortcomings in their lifestyle, which had a demonstrable effect on their flight performance. In the 1950 s and 1960s, it was mainly the quality of the food, the water intake regime and sometimes the rest regime. In the 1970s and 1980s, with advances of knowledge in the medical field, the pilots' lifestyle became, with occasional irregularities, stable and relatively well-balanced. However, since 1990s the imbalances in lifestyle have been growing again. The questionnaire survey conducted among flight personnel of the Air Force of the Army of the Czech Republic found that the quality of food and water intake regime is at a very good level, but the quality of physical training and the balance of work and rest in particular have deteriorated.

Physical readiness is currently, to a large extent, a matter of personal decision and attitude, although there is a wide range of inspiring professional literature on the subject. The problem is exacerbated by the fact that, due to high staff turnover and a shortage of staff on shifts, there has been a shift from collective to individual sports. 
Then, with a great deal of fatigue and stress, finding motivation to exercise is much harder for an individual than for a team member.

According to the results of the questionnaire survey, the ubiquitous stress and physical and mental fatigue appear to be the biggest problem. This is mainly due to the high stress level an individual is exposed to in understaffed workplaces. There is also pressure to increase performance from the employer in the form of financial motivation and employment uncertainty after the compulsory employment for the Army of the Czech Republic, a compensation for the pilot's free university education, has ended. The fact that the issue of good lifestyle is not currently included in the pilots' training programs also largely contributes to this. The pilots are not sufficiently aware of what to do and how to do things right or where to seek help if they have a longstanding problem, such as poor sleep or ineffective mental regeneration, which are very frequent. Intensive work is currently being done to eliminate this systemic shortcoming.

\subsection{Mental Hygiene}

Mental hygiene is the science of rules and methods aimed at maintaining, enhancing or regaining mental health. "Mental health" is a mental condition that is not associated with the presence of symptoms of mental illness, imbalance or adaptation disorders [12].

The fundamental methods of mental health care include: sufficiently long and quality SLEEP, healthy and balanced FOOD, regular EXERCISE, proper TIME MANAGEMENT, RELAXATION and SELF-REGULATING EXERCISES. The main goal of the application of principles of mental hygiene is to achieve a state where one does not "live in conflict with oneself".

There is currently a considerable amount of literature, video recordings of lectures by experts and other information sources where the necessary instructions can be obtained. Their choice depends on the current needs of the individual, so a universal source cannot be recommended. Everyone must find their source of information that will meet their individual needs in terms of its content and form.

It is also possible to draw upon the services of medical specialists (sleep, diet), psychotherapists (relaxation and self-regulating exercises) or, in certain areas, mental coaches (time management). Sleep laboratories can also offer very effective help, providing counseling services as well as specific examinations focused on the identification and treatment of sleep disorders [13].

Awareness of these methods and fields of study is currently very low among military pilots of the Air Force of the Army of the Czech Republic, although it could significantly reduce the risks of adverse mental conditions during their professional careers. Therefore, it is necessary to pay attention to those fields in the educational programs for members of flight crew and not to underestimate their importance. Intensive work is currently being done to eliminate also this systemic shortcoming.

\section{Conclusion}

As follows from the above analysis, the biggest challenge for pilots of any age and focus is not to master the aircraft, but to master oneself - to control their emotions in complex life situations and subjective mental states arising from them. It is only mental balance that allows making full use of the potential of an individual and it is the real key to achieving piloting excellence. 
To conclude, the author would like to express his respect for the work of and to honor the memory of flight crews killed in the above-analyzed air disasters. From the experience they gained and expensively paid for we can now draw on and learn for the future of flying and flight safety.

This study will be used by the Air Force of the Army of the Czech Republic to support the further development of flight safety.

\section{References}

[1] Flight Safety [Regulation] (in Czech). Prague: Ministry of Defense, 2006.

[2] Flight Safety [Order of the Minister of Defense No. 13/2016 of the Journal]. Prague: Ministry of Defense, 2016.

[3] Information System for Logistics of Ministry of Defense and the Army of the Czech Republic (ISL) [Software]. AURA, Inc.

[4] Military Central Archives: Homepage [online]. Prague, 2010 [viewed 2018-02-10]. Available from: http://www.vuapraha.cz/

[5] Military Central Archives: Administrative Archives of the Armed Forces of the Czech Republic [online]. Prague, 2010 [viewed 2018-02-10]. Available from: http://www.vuapraha.cz/archiv-ACR

[6] SLAVÍK, S. Overview of Aviation Accidents, Serious Preconditions and Preventive Experience (Book 1) (in Czech). Hradec Králové, 1979.

[7] SLAVÍK, S. Overview of Aviation Accidents, Serious Preconditions and Preventive Experience (Book 2) (in Czech). Hradec Králové, 1979.

[8] SLAVÍK, S. Overview of Aviation Accidents, Serious Preconditions and Preventive Experience (Book 3) (in Czech). Hradec Králové, 1981.

[9] SLAVÍK, S. Overview of Aviation Accidents, Preconditions and Preventive Experience 1981-1982 (in Czech). Hradec Králové, 1986.

[10] SLAVÍK, S. Overview of Aviation Accidents, Preconditions, Deficiencies and Preventive Experience 1983-84 (in Czech). Hradec Králové, 1989.

[11] ZAVILA, O. and R. CHMELÍK. Ejection Causes in Military Jet Aircraft in Czechoslovakia and the Czech Republic. Advances in Military Technology, 2019, 14(1), pp. 5-20. DOI 10.3849/aimt.01253.

[12] MÍČEK, L. Mental Hygiene (in Czech). Prague: SPN, 1984.

[13] Vyspi se: List of Sleep Laboratories. (in Czech) [online]. [viewed 2020-09-10]. Available from: https://www.vyspise.cz/article/cz/seznam-spankovych-laboratori 